\title{
Forensic differentiation of diesel fuels using hydrocarbon isotope fingerprints
}

\author{
Syahidah A. Muhammad* \\ Department of Chemistry, University of Otago, Otago \\ School of Industrial Technology, Universiti Sains \\ Malaysia
}

\author{
Alan R. Hayman \\ Department of Chemistry, University of Otago, Otago
}

\author{
Russell D. Frew \\ Department of Chemistry, University of Otago, \\ Otago \\ FAO/IAEA Division of Nuclear Techniques \\ in Food and Agriculture, Vienna, Austria
}

\begin{abstract}
Compound-specific isotope analysis (CSIA) is fast becoming an important tool to provide chemical evidence in a forensic investigation. Attempts to trace environmental oil spills were successful where isotopic values were particularly distinct. However, difficulties arise when a large dataset is analyzed and the isotopic differences between samples are subtle. Thus, this study intends to demonstrate any linkages between diesel fuels in a large number of datasets where subtlety in the isotopic values is accentuated by the near single-point source of origin. Diesel fuels were obtained from various locations in the South Island of New Zealand. Aliquots of these samples were diluted with $n$-pentane and subsequently analyzed with gas chromatography-isotope ratio mass spectrometry (GC-IRMS) for carbon and hydrogen isotope values. The data obtained were subjected to principal component analysis (PCA) and hierarchical clustering. A wide range of $\delta^{13} \mathrm{C}$ and $\delta^{2} \mathrm{H}$ values were determined for the ubiquitous alkane compounds (the greatest values being $-4.5 \%$ and $-40 \%$, respectively). Based on the isotopic character of the alkanes it is suggested that diesel fuels from different locations were distinguishable and that the key components in the differentiation are the $\delta^{2} \mathrm{H}$ values of the shorter chain-length alkanes. However, while the stable isotope measurements may provide information to classify a sample at a broad scale, much more detailed information is required on the temporal and spatial variability of diesel compositions. The subtle differences of the stable isotope values within the alkanes of different diesel fuels highlighted the power of CSIA as a means of differentiating petroleum products of different origins, even more so when two or more stable isotopes data are combined. This paper shows that CSIA when used in tandem with multivariate statistical methods can provide suitable tools for source apportionment of hydrocarbons by demonstrating a straightforward approach, thus eliminating lengthy analytical processes.
\end{abstract}

Key words: diesel fuel, alkane, compound-specific isotope analysis (CSIA), principal component analysis (PCA), hierarchical clustering

\footnotetext{
Addresses: S. A Muhammad, R. D. Frewac, A. R. Hayman: P.O. Box 56, Dunedin 9054, New Zealand. *Corresponding author at: 11800 Minden, Pulau Pinang, Malaysia. e-mail: syahidah.muhammad@usm.my.

Received: March 30, 2013; accepted: June 21, 2013
} 


\section{Introduction}

Traceability of diesel fuel is becoming increasingly important especially in a forensic context. From an environmental perspective it is important to ascertain culpability for a diesel oil spill; likewise in a criminal investigation, such as the theft of diesel fuel. In either situation, it is important to demonstrate any linkages, or relationships, between diesel samples. Molecular fingerprinting provides obscure and ambiguous information based on chemical fingerprints of the refined petroleum products; more effective tools are required to withstand scrutiny in the court of law. Compound-specific isotope analysis (CSIA) has been shown to distinguish petroleum-derived hydrocarbon samples of different origin and/or history based on the stable isotope signatures, albeit the differences obtained are subtle (O'Malley et al. 1996; Smallwood et al. 2002; Philp et al. 2002; O'Sullivan and Kalin 2008). The objective of this study is to explore the discriminative power of CSIA to find the relatedness in a set of diesel fuel samples, and thus provide insights in the changes occurring in the isotopic signatures of refined petroleum products, if any. If changes are documented, then scientists will have to be more cautious in applying this method and certainly isotopic shifts should be accounted for when presenting isotope fingerprints data. More importantly, this research was carried out in New Zealand, where almost $90 \%$ of the domestic diesel usage comes from the same refinery, which will give strength to the investigation as the samples obtained originate from a near singlepoint source.

Scientific literature shows that the isotopic composition of individual compounds within diesel oil is dependent upon its geologic source, processing and decompositional state (McRae et al. 1996). However, after the diesel oil leaves the refinery, it is also subjected to a variety of physical and biological processes which begin to alter the isotopic composition of the individual compounds in the refined oil. These processes could occur simultaneously and overlap with each other. Nevertheless, the likelihood of diesel oil stored in a tank to undergo biological weathering is small if the service station operator adheres to good "house keeping" practices, i.e. treatment with biocides to limit growth and the use of special tank linings, etc. (Muthukumar et al. 2003) which leaves only abiological processes such as physical mixing and partial evaporation to affect the isotopic composition of the hydrocarbons.

As diesel weathers, some compounds, such as alkanes, undergo isotopic fractionation (Sun et al. 2003; 2005) _ENREF_3. No fractionation is observed for carbon or hydrogen during light weathering, but carbon fractionation up to $4 \%$ has been observed during heavy weathering (Sun et al. 2005). Fractionation of up to $35 \%$ has been observed for hydrogen during heavy weathering (Sun et al. 2005). These changes are $>10$ times the analytical precision; thus the isotopic fingerprint has a high level of discriminatory power and can be used to differentiate batches of diesel that have different weathering history. 
Developments in GC-IRMS (Matthews and Hayes 1978; Freeman et al. 1990; Lichtfouse 2000) have enabled CSIA techniques to be applied in a wide range of studies of hydrocarbons ENREF 5 ENREF 6. It has been used to aid source rock and oil correlations (Asif et al. 2009), source-apportioned polycyclic aromatic hydrocarbon (PAH) emissions (McRae et al. 1996), distinguishing gasoline samples (Smallwood et al. 2002), and many others reviewed elsewhere (MeierAugenstein 1999; Philp 2007; Thullner et al. 2012; Négrel et al. 2012). More importantly, many studies have proven the variability of carbon and hydrogen isotopic compositions of individual compounds within gasoline samples (Dempster et al. 1997; Kelley et al. 1997; Harrington et al. 1999; Smallwood et al. $2001,2002)$. However, studies on the variability of the stable isotope compositions in hydrocarbons within diesel fuel are severely lacking (Li et al. 2001; Harvey et al. 2012). Although both gasoline and diesel fuel contain hydrocarbon compounds that are derived from the same source (crude petroleum), they differ in their chemical properties and behaviors (Speight 2007). Gasoline is composed of hydrocarbon compounds which are light, clear liquid, and have short carbon chain lengths $(<\mathrm{C} 12)$ which easily vaporize; this makes gasoline a good and preferred study sample to look for isotopic variation and discrimination, as vaporization fractionates isotopes (Kendall and Caldwell 1998). On the other hand, diesel fuel distills at a high temperature $\left(>230^{\circ} \mathrm{C}\right)$ and contains compounds of similar molecular masses which produce similar chromatograms, even for the ones derived from different crude oil feedstocks (Wang et al. 1999). Furthermore, diesel fuel does not contain many source-specific target analytes which confound the discrimination and correlation analysis of this refined petroleum product. Diesel fuel is a challenge to fingerprint and while conventional GC techniques lack the resolving power to detect minor differences between similar samples (Gaines et al. 2006), CSIA can potentially be a unique tool to differentiate batches of neat petroleum diesels; hence the rationale for this study.

Difficulties in the determination of source and origin of diesel fuel are compounded if the parent crude oil comes from the same geologic province and background, or if crude oil from various areas is brought into a country and processed at the same petroleum refining plant, such as the case in New Zealand. Chemical variability of the diesel fuel distributed for domestic use in this country is expected to be very low due to several factors in its supply chain; 1). the Marsden Point Oil Refinery (the only refinery in the country) produces around $90 \%$ of New Zealand's diesel and about $65 \%$ of its petrol, 2). the rest of New Zealand's petrol and diesel is imported from refineries in the Asia-Pacific region and sometimes as far away as the USA and the Middle East, 3). the four major oil companies (BP, Caltex, Mobil and Shell) supply more than 95\% of the petrol and diesel sold in New Zealand, 4). the Marsden Point Refinery receives a processing fee from each oil company. It does not select the oil it processes, nor does it own any of the crude oil or the products it produces, 5). with the takeover of Challenge by Caltex, there is only one independent retail fuel operator, Gull Petroleum, in 
New Zealand. Gull Petroleum imports all its fuel directly through its terminal in Mt. Maunganui.

Significant isotopic differences would be expected between different suppliers, feedstocks, or if the same supplier uses different starting crude oil blends (Smallwood et al. 2002). However, in the New Zealand context, the near-single point of supply to the major distributors would mean the differences between oil company's products would be much more subtle. Differences would be imparted mainly through mixing in the various reservoirs and storage tanks in the supply chain and physical weathering (evaporation) effects. The fuel dispensed at each service station will have a different history and hence likely a different isotopic composition. It is with this assumption that we carried out the analysis of 45 diesel fuels obtained from different service stations using the CSIA technique. If the objective of this analysis is achieved, it will provide supportive evidence of the robustness and the discriminative power of the technique.

Multivariate statistics have been used to correlate and differentiate petroleum hydrocarbons to its source(s) based on the stable isotope fingerprints in recent times (Boyd and Coffin 2004; Boyd et al. 2006). These methods are suitable for environmental hydrocarbon fingerprinting due to the large number of samples and variables involved. Exploratory analysis such as principal component analysis (PCA) is an approach which is frequently applied in this area due to its ability to detect a potential group tendency between samples; i.e. to assign a class membership to each sample and at the same time revealing the underlying features in the data set that are responsible for the detected classification (Pasadakis et al. 2008). Another statistical approach which is highly favored for oilsource correlation work is hierarchical clustering analysis. This approach builds models based on distance connectivity between samples in a multidimensional space spanned by the original variables. It aims to assign each sample to a group of objects in a stepwise manner where extensive hierarchies of clusters merge with each other at certain distances.

The objective of the present study is to analyze a large number of diesel fuels obtained from various parts of the South Island of New Zealand in an attempt to find linkages between the samples based on the isotopic signatures of the selected alkanes present in the samples. The data set obtained was subjected to PCA and hierarchical clustering analysis to evaluate information about the similarities and dissimilarities of the diesel samples, and at the same time ascertain the variables that provide the best interpretation within the data set.

Similar work on the characterization of diesel fuel using isotopic fingerprints has been recently reported (Harvey et al. 2012) but the present study includes a more extensive sample population with the prospect of having a near-single point of supply; this provides an additional challenge in differentiating diesel fuels based on the stable isotope fingerprints. 


\section{Material and methods}

Sample details and preparation

Diesel fuel samples were obtained from 45 service stations located around the South Island of New Zealand coming from areas such as Dunedin City, North and South Otago, Twizel, Christchurch City and South Canterbury. Although Twizel is located in inland Canterbury it is generally serviced from the Otago arterial road network. The suppliers of the 45 different diesel fuels include Caltex, Mobil, Challenge, Shell and BP. A map of the South Island of New Zealand showing the aforementioned areas is shown in Fig. 1.

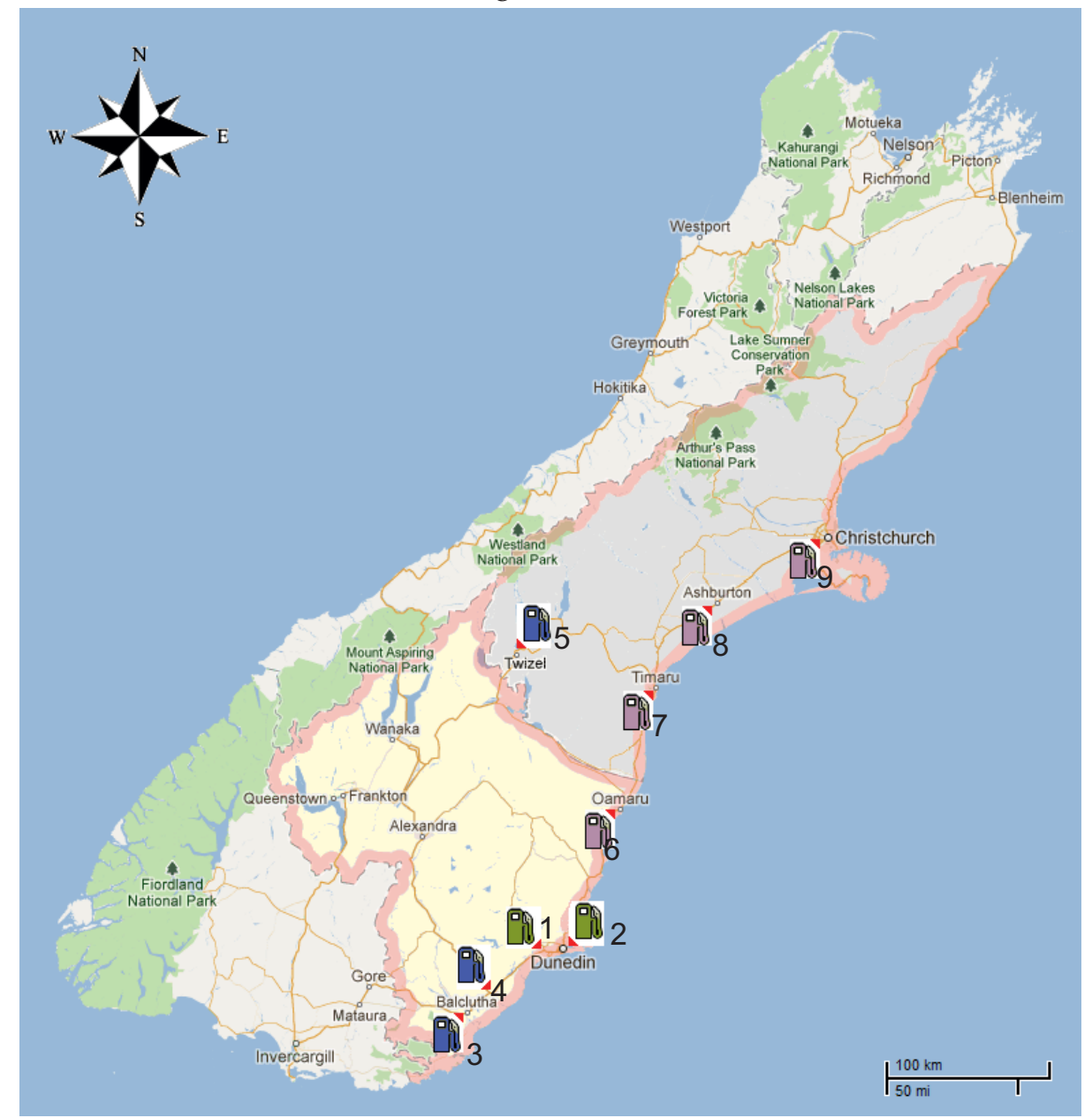

Fig. 1

A map of the South Island of New Zealand showing the locations of the service stations where the 45 diesel samples were obtained. Locations were marked as follows: Dunedin City $(1,2)$, Canterbury region and North Otago $(3,4,5)$, South Otago and Twizel $(6,7,8,9)$ 
The diesel fuels were prepared for GC analysis by sub-sampling $20 \mu \mathrm{L}$ of each sample and dispensed using a micro syringe into a GC vial which was then diluted to $2 \mathrm{ml}$ with $n$-pentane. All samples were prepared in duplicate.

\section{GC analysis}

Compound-specific carbon and hydrogen isotope ratios were determined using a Trace Ultra-gas chromatograph (Thermo, Milan, Italy) coupled to a Deltaplus XP isotope ratio mass spectrometer (Thermo, Bremen, Germany) via a high-temperature conversion furnace. For carbon isotope analysis the individual compounds were converted to $\mathrm{CO}_{2}$ in a reactor at $940{ }^{\circ} \mathrm{C}$ with $\mathrm{Pt}, \mathrm{Ni}$, and $\mathrm{Cu}$ wires to promote combustion. Hydrogen isotopes were measured after conversion of the sample to $\mathrm{H}_{2}$ by pyrolysis in an empty ceramic reactor held at $1450{ }^{\circ} \mathrm{C}$. The injection mode used was splitless with the temperature set at $300{ }^{\circ} \mathrm{C}$. One $\mu \mathrm{L}$ of sample was injected using a CombiPAL auto sampler (CTC, Zwingen, Switzerland). Compounds were separated using a J\&W Scientific HP-1 GC column ( $30 \mathrm{~m}, 0.32 \mathrm{~mm}$ i.d., $0.25 \mu \mathrm{m}$ film thickness). Identification of the analytes was made prior to isotope analysis using a gas chromatograph with a flame ionization detector (GC-FID) by comparing the retention times of a DRH-008S-R2 hydrocarbon standard solution (AccuStandard, Connecticut, USA), which contains $35 n$-alkane compounds in chloroform, with those of the samples. The GC analytical conditions for both instruments were set to be the same throughout each run to avoid misrepresentation. The carrier gas for the analysis was helium with a constant flow of $1.5 \mathrm{ml} / \mathrm{min}$. The parameters for the analytical run were as follows: $50{ }^{\circ} \mathrm{C}$ initial value for the oven temperature program, initial hold time of $1 \mathrm{~min}$, temperature ramp at $10^{\circ} \mathrm{C}$ min to $300{ }^{\circ} \mathrm{C}$, and final hold time of $4 \mathrm{~min}$. Gas chromatographic and isotope analyses were obtained on at least two replicate samples and each analysis was an average of at least three measurements.

Instrumental drift during individual sample analysis ( $30 \mathrm{~min}$ ) was corrected by injecting multiple pulses of monitoring gas $\left(\mathrm{CO}_{2}\right.$ and $\mathrm{H}_{2}$ for each of their respective analysis) at the beginning and end of each sample run. Instrumental drift during a batch sample was corrected by injecting a standard mixture (containing seven pre-determined bulk $\delta^{13} \mathrm{C}$ and $\delta^{2} \mathrm{H}$ isotope ratio $n$-alkanes) every six samples. The instrument analytical precision for compound specific $\delta^{13} \mathrm{C}$ and $\delta^{2} \mathrm{H}$ analysis was determined to be $<0.3 \%$ and $3 \%$, respectively, based on the results for the external standard containing $7 n$-alkanes measured after every 6 samples. Isotopic compositions of each $n$-alkane are expressed as $\delta$ values per mil (\%o) deviation relative to isotopic standard reference materials:

$$
\delta=\left[\left(\mathrm{R}_{\text {sample }} / \mathrm{R}_{\text {standard }}\right)-1\right]
$$

where $\mathrm{R}={ }^{13} \mathrm{C} /{ }^{12} \mathrm{C}$ or ${ }^{2} \mathrm{H} /{ }^{1} \mathrm{H}$. The $\delta^{13} \mathrm{C}$ were reported relative to the Vienna Pee Dee Belemnite (VPDB) scale, while $\delta^{2} \mathrm{H}$ values were reported relative to the 
Vienna Standard Mean Ocean Water (VSMOW) standard. The $\mathrm{H}_{3}{ }^{+}$factor was determined daily using the standard hydrogen gas introduced through the interface. The mass spectrometer was tuned to ensure that the $\mathrm{H}_{3}{ }^{+}$factor was less than $10 \mathrm{ppm} / \mathrm{nA}$ and that the daily variability is $<0.1 \mathrm{ppm} / \mathrm{nA}$.

\section{Isotopic composition of alkanes in diesel fuel}

Diesel fuel is a very complex mixture of thousands of individual compounds, most with carbon numbers between 9 and 23. The alkanes' (also known as paraffins) proportion in diesel fuel typically amount to 75 weight $\%$, the remainder being mainly naphthenes and aromatic fractions. This complexity can cause analytical problems as true compound-specific isotopic analysis requires baseline resolution and no co-eluting peaks. In a typical gas chromatographic profile, middle range molecular weight alkanes are concentrated in the middle of the profile with $n \mathrm{C}_{15}, n \mathrm{C}_{16}, n \mathrm{C}_{17}$, pristane, $n \mathrm{C}_{18}$, phytane and $n \mathrm{C}_{19}$ compounds, as can be seen in Fig. 2. The measured stable isotope ratios across selected peaks may therefore include some underlying co-eluting material and are not entirely specific for individual compounds. However, the data remain forensically relevant as part of an "isotopic fingerprint pattern". The alkane compounds which were able to be reliably quantified and yielded reproducible isotopic values using a GC-IRMS system in this study started with $n \mathrm{C}_{12}$ and ended with $n \mathrm{C}_{23}$. The responses from these compounds give reproducible results when they are in the linear range of the instrument capability which is at $0.5 \mathrm{~V}$ or more (Bilke and Mosandl 2002; Schmitt et al. 2003). Hence, in this study we solely focused our attention on these selected alkanes $\left(n \mathrm{C}_{12}\right.$ to $\left.n \mathrm{C}_{23}\right)$.

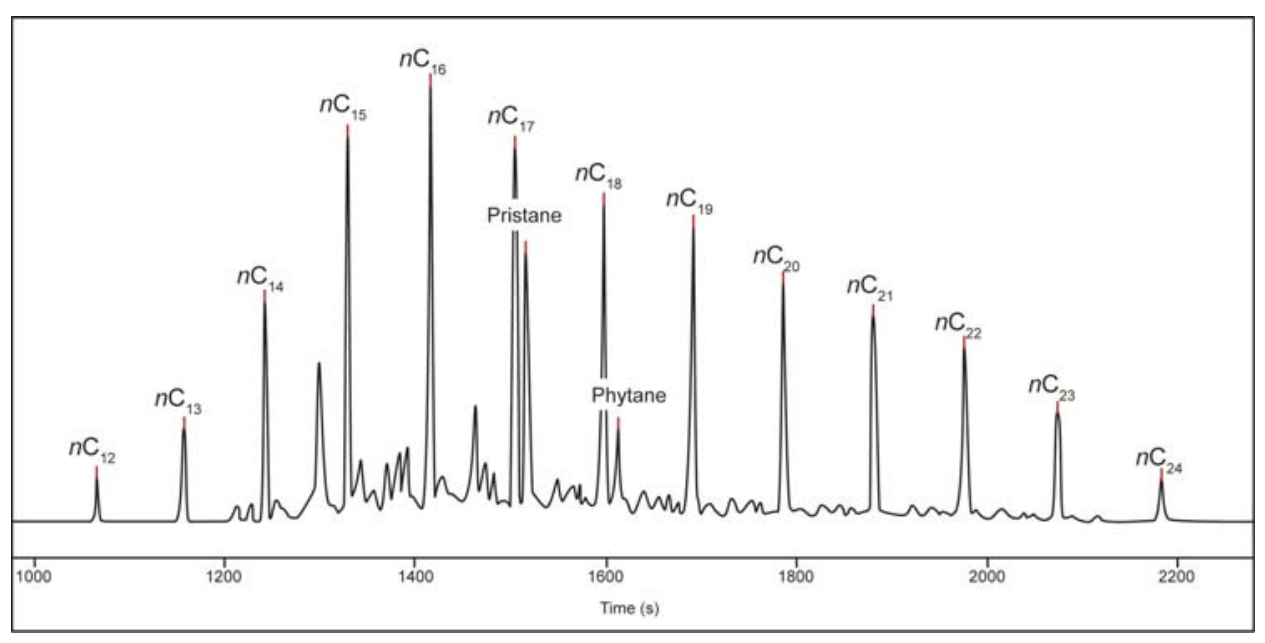

Fig. 2

Typical chromatogram of a diesel fuel analysed by GC-IRMS 


\section{Data treatment using statistical methods}

All mathematical and statistical computations were made using Excel 2007 (Microsoft Office ${ }^{\circledR}$ ), SigmaPlot 11.0 (Systat Software Inc. ${ }^{\circledR}$ ) and SPSS 16.0 (IBM ${ }^{\circledR}$ ). Multivariate statistical analysis of the stable isotope data was performed using PCA and hierarchical clustering techniques.

PCA is a mathematical procedure that converts the possibly correlated original variables into new linearly uncorrelated variables, called the principal components (PCs). PCA reveals the internal structure of the data and finds the indices which best explain the variance in the data set. This technique also provides the most meaningful parameters which describe the whole data set interpretation, reducing the dimensionality of the transformed data and summarizing the statistical correlation among constituents with minimum loss of original information (Kazi et al. 2009). In this study, PCA was used as an exploratory technique to determine samples with similar isotopic compositions in the PC space. This can be visualized using the scores plot, which illustrates a sample grouping tendency as the position of each sample in the scores space depending on the contribution of certain characteristic patterns (loadings) of the data set (Pasadakis et al. 2008).

Hierarchical clustering analysis seeks to build a hierarchy of clusters by measuring either the distance or the similarity between the objects to be clustered. It is normally used when there are no a priori hypotheses. The more preferred approach is the hierarchical agglomerative clustering or the "bottom up" approach, which builds the hierarchy from the individual element by progressively merging the clusters. The results of hierarchical clustering are normally illustrated using a dendrogram (tree diagram). The dendrogram illustrates the clustering summary processes, showing the number of clusters (number criterion) and indicating their proximity in space (distance criterion), thus reducing the dimensionality of the original data. In this study, hierarchical clustering analysis was performed on the data using Ward's linkage method, which minimizes the total within-cluster variance, and the cluster distances are defined by the squared Euclidean distances as a measure of similarity.

\section{Results and discussions}

\section{CSIA of diesel fuels from service stations}

The stable isotope values of the $12 n$-alkanes, pristane and phytane were monitored to discriminate diesel fuels from different sources. The ranges in carbon and hydrogen isotope ratios of each of these alkanes are illustrated in Figs 3 and 4 , respectively. The range of carbon isotopic compositions of the alkanes in all of the diesel samples ( -33.3 to $-25.8 \%$ o $)$ was found to be similar to previous work (Sun et al. 2005). The $\delta^{13} \mathrm{C}$ and $\delta^{2} \mathrm{H}$ values of pristane and phytane were lighter than the rest of the alkane compounds, which is probably due to the 


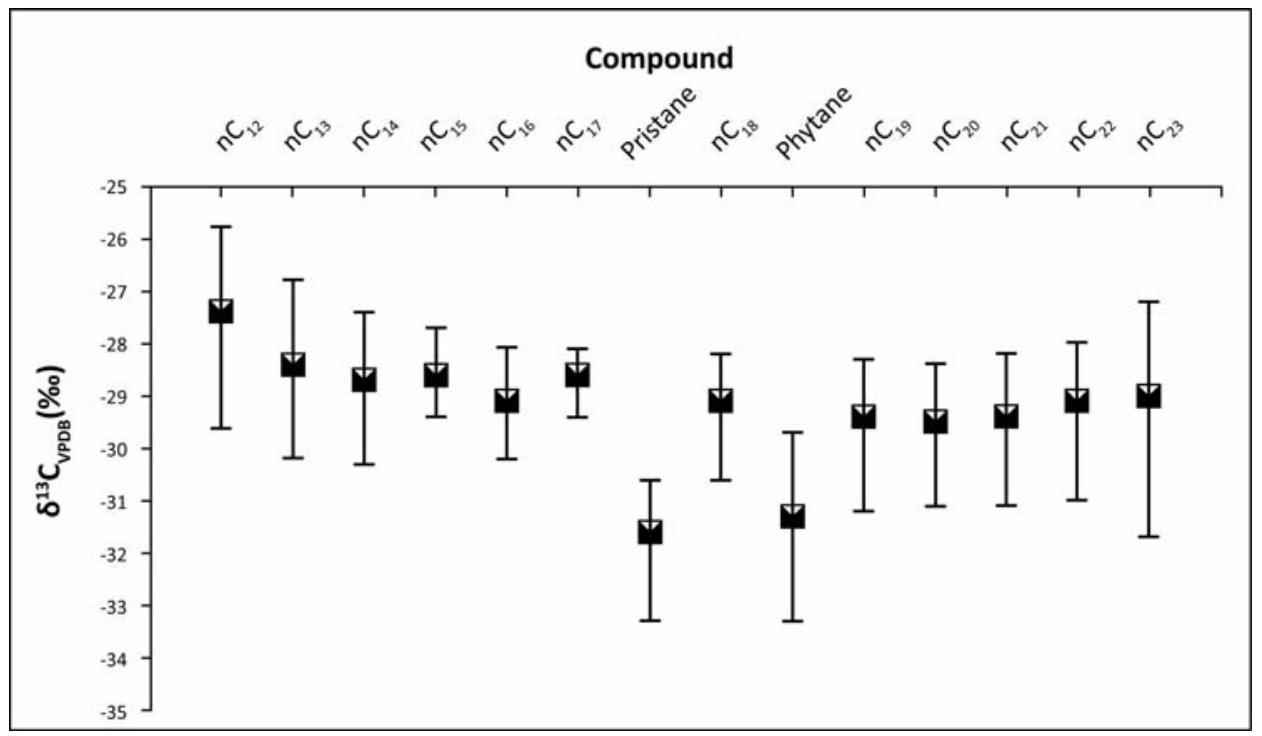

Fig. 3

Carbon isotope ratios of the alkane compounds found in 45 diesel samples. Bars represent the range of isotope values for each compound

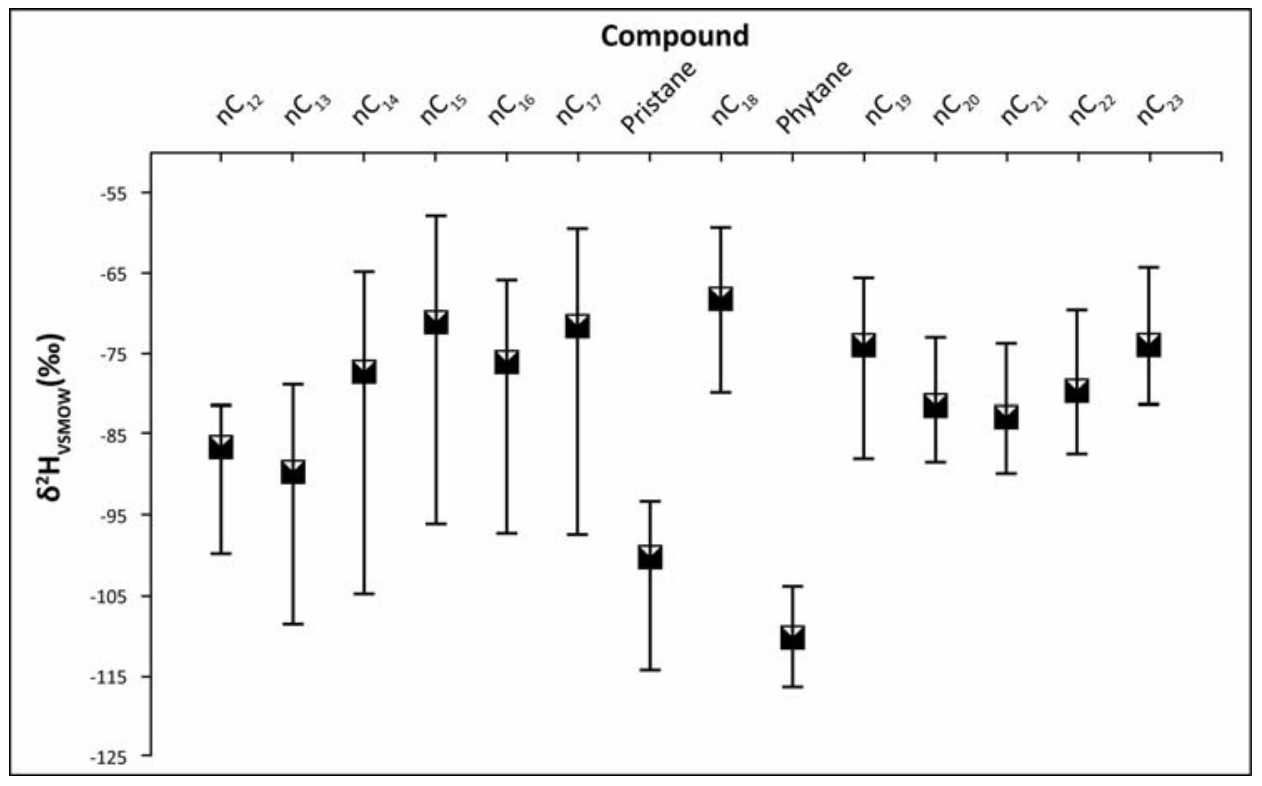

Fig. 4

Hydrogen isotope ratios of the alkane compounds found in 45 diesel samples. Bars represent the range of isotope values for each compound 
different biosynthetic pathways undergone by these isoprenoids during biogenic processes (Bayliss 1968). Most petroleum and its related products are known to have $\delta^{13} \mathrm{C}$ values of $-34 \%$ o to $-20 \%$ (Fuex 1977), and extremely low carbon isotope ratios $(-62 \%$ to $-31 \%$ ) of natural gas from biogenic origin have been reported (McRae et al. 2000).

Table 1 shows the statistics of the $\delta^{13} \mathrm{C}$ and $\delta^{2} \mathrm{H}$ values of individual alkanes in 45 diesel samples from local service stations. Alkane compounds in these diesel fuels exhibited a broad range of $\delta^{13} \mathrm{C}$ within the sample group as a whole, the greatest being observed for $n \mathrm{C}_{23}(-31.7$ to $-27.2 \%)$ and $n \mathrm{C}_{12}(-29.6$ to $-25.8 \%$ ). The statistical data show the hydrogen isotope ratios having the biggest range in $n \mathrm{C}_{14}$ (-105.1 to $-65.1 \% o), n \mathrm{C}_{15}\left(-96.2\right.$ to $-58.1 \%$ ) and $n \mathrm{C}_{17}(-97.6$ to $-59.7 \%$ ) in the entire diesel samples analyzed. The wide range of hydrogen isotope values for these alkanes within the diesel fuels were in agreement with previous published results, each of which were distinctive isotopically (Li et al. 2001).

\section{Multivariate statistical analyses of the isotopic values}

PCA was used to identify clusters of similar diesels and the most discriminatory compounds in the data set. The scree plot in Fig. 5 shows the trend line indicating the fraction of total variance in the data. The variance was explained mostly by three components; the alkane compounds that contributed predominantly to the

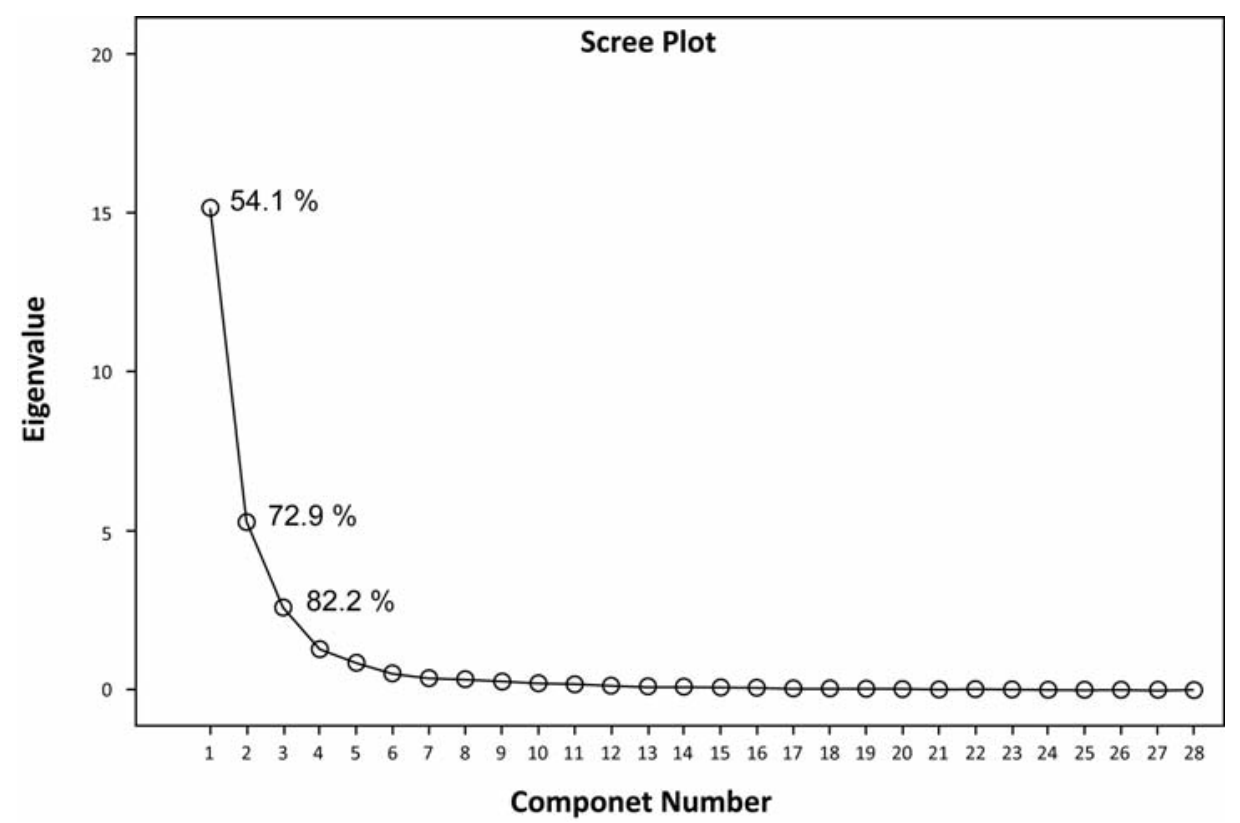

Fig. 5

Scree plot shows the trend line indicating the fraction of total variance in the data. The variance is explained mostly by three components 
Forensic differentiation of diesel fuels using hydrocarbon isotope fingerprints 29

Table 1

Statistics of the $\delta^{13} \mathrm{C}$ and $\delta^{2} \mathrm{H}$ value of individual alkanes in 45 diesel samples from local service stations

\begin{tabular}{|c|c|c|c|c|c|c|c|}
\hline & $\mathrm{N}$ & $\begin{array}{c}\text { Range } \\
\% \circ\end{array}$ & $\begin{array}{c}\text { Minimum } \\
\delta(\% \circ)\end{array}$ & $\begin{array}{c}\text { Maximum } \\
\delta(\%)\end{array}$ & $\begin{array}{l}\text { Mean } \\
\delta(\%)\end{array}$ & $\begin{array}{c}\text { Std. } \\
\text { Deviation }\end{array}$ & Variance \\
\hline$n \mathrm{C}_{12}{ }^{13} \mathrm{C}$ & 45 & 3.9 & -29.6 & -25.8 & -27.4 & 0.9 & 0.9 \\
\hline$n \mathrm{C}_{13}{ }^{13} \mathrm{C}$ & 45 & 3.3 & -30.2 & -26.8 & -28.4 & 0.9 & 0.9 \\
\hline$n \mathrm{C}_{14}{ }^{13} \mathrm{C}$ & 45 & 2.8 & -30.3 & -27.4 & -28.7 & 0.6 & 0.4 \\
\hline$n \mathrm{C}_{15}{ }^{13} \mathrm{C}$ & 45 & 1.6 & -29.4 & -27.7 & -28.6 & 0.4 & 0.1 \\
\hline$n \mathrm{C}_{16}{ }^{13} \mathrm{C}$ & 45 & 2.1 & -30.2 & -28.1 & -29.1 & 0.4 & 0.2 \\
\hline$n \mathrm{C}_{17}{ }^{13} \mathrm{C}$ & 45 & 1.3 & -29.4 & -28.1 & -28.6 & 0.4 & 0.1 \\
\hline Pris ${ }^{13} \mathrm{C}$ & 45 & 2.7 & -33.3 & -30.6 & -31.6 & 0.9 & 0.7 \\
\hline$n \mathrm{C}_{18}{ }^{13} \mathrm{C}$ & 45 & 2.4 & -30.6 & -28.2 & -29.1 & 0.7 & 0.4 \\
\hline $\mathrm{Phy}{ }^{13} \mathrm{C}$ & 45 & 3.6 & -33.3 & -29.7 & -31.3 & 1.0 & 0.9 \\
\hline$n \mathrm{C}_{19}{ }^{13} \mathrm{C}$ & 45 & 2.9 & -31.2 & -28.3 & -29.4 & 0.7 & 0.5 \\
\hline$n \mathrm{C}_{20}{ }^{13} \mathrm{C}$ & 45 & 2.7 & -31.1 & -28.4 & -29.5 & 0.6 & 0.4 \\
\hline$n \mathrm{C}_{21}{ }^{13} \mathrm{C}$ & 45 & 2.9 & -31.1 & -28.2 & -29.4 & 0.8 & 0.7 \\
\hline$n \mathrm{C}_{22}{ }^{13} \mathrm{C}$ & 45 & 3.0 & -31.0 & -28.0 & -29.1 & 0.8 & 0.7 \\
\hline$n \mathrm{C}_{23}{ }^{13} \mathrm{C}$ & 45 & 4.5 & -31.7 & -27.2 & -29.0 & 1.2 & 1.5 \\
\hline$n \mathrm{C}_{12}{ }^{2} \mathrm{H}$ & 45 & 19 & -100 & -82 & -87 & 4 & 21 \\
\hline$n \mathrm{C}_{13}{ }^{2} \mathrm{H}$ & 45 & 30 & -109 & -79 & -90 & 7 & 54 \\
\hline$n \mathrm{C}_{14}{ }^{2} \mathrm{H}$ & 45 & 40 & -105 & -65 & -78 & 11 & 121 \\
\hline$n \mathrm{C}_{15}{ }^{2} \mathrm{H}$ & 45 & 38 & -96 & -58 & -71 & 11 & 128 \\
\hline$n \mathrm{C}_{16}{ }^{2} \mathrm{H}$ & 45 & 31 & -98 & -66 & -76 & 8 & 71 \\
\hline$n \mathrm{C}_{17}{ }^{2} \mathrm{H}$ & 45 & 38 & -98 & -60 & -72 & 11 & 123 \\
\hline $\operatorname{Pris}^{2} \mathrm{H}$ & 45 & 21 & -115 & -93 & -100 & 4 & 19 \\
\hline$n \mathrm{C}_{18}{ }^{2} \mathrm{H}$ & 45 & 20 & -80 & -60 & -68 & 5 & 26 \\
\hline $\mathrm{Phy}^{2} \mathrm{H}$ & 45 & 13 & -117 & -104 & -110 & 3 & 9 \\
\hline$n \mathrm{C}_{19}{ }^{2} \mathrm{H}$ & 45 & 23 & -88 & -66 & -74 & 5 & 25 \\
\hline$n \mathrm{C}_{20}{ }^{2} \mathrm{H}$ & 45 & 15 & -89 & -73 & -81 & 5 & 21 \\
\hline$n \mathrm{C}_{21}{ }^{2} \mathrm{H}$ & 45 & 16 & -90 & -74 & -83 & 4 & 20 \\
\hline$n \mathrm{C}_{22}{ }^{2} \mathrm{H}$ & 45 & 18 & -88 & -70 & -80 & 5 & 29 \\
\hline$n \mathrm{C}_{23}{ }^{2} \mathrm{H}$ & 45 & 17 & -81 & -65 & -74 & 5 & 21 \\
\hline
\end{tabular}


variance were identified by using the first principal component (PC1). About $54 \%$ of the variability was explained by PC1. Another 19\% of the data set variability was accounted for by the second principal component (PC2). The third principal component (PC3) described $9 \%$ of the variance and altogether more than $82 \%$ of the data set variability could be described by the first three principal components.

Figures 6 and 7 show the scores plot for the first three principal components of the data set. Plotting PC1 and PC2 yielded three distinct clusters (Fig. 6). The first cluster consisted of South Otago and Twizel samples, the second cluster contained the samples from Dunedin City area and the third consisted of the remaining samples. Likewise, plotting PC1 and PC3 in Fig. 7 also produced three distinct clusters but this time providing a clearer separation between South Otago and Twizel samples from the Canterbury region and North Otago samples, as well as the diesel samples obtained from the Dunedin City area. Overall, plotting all three PCs on the scatter plot inferred very close relationships between samples in two different clusters, one of which consisted of samples coming from the

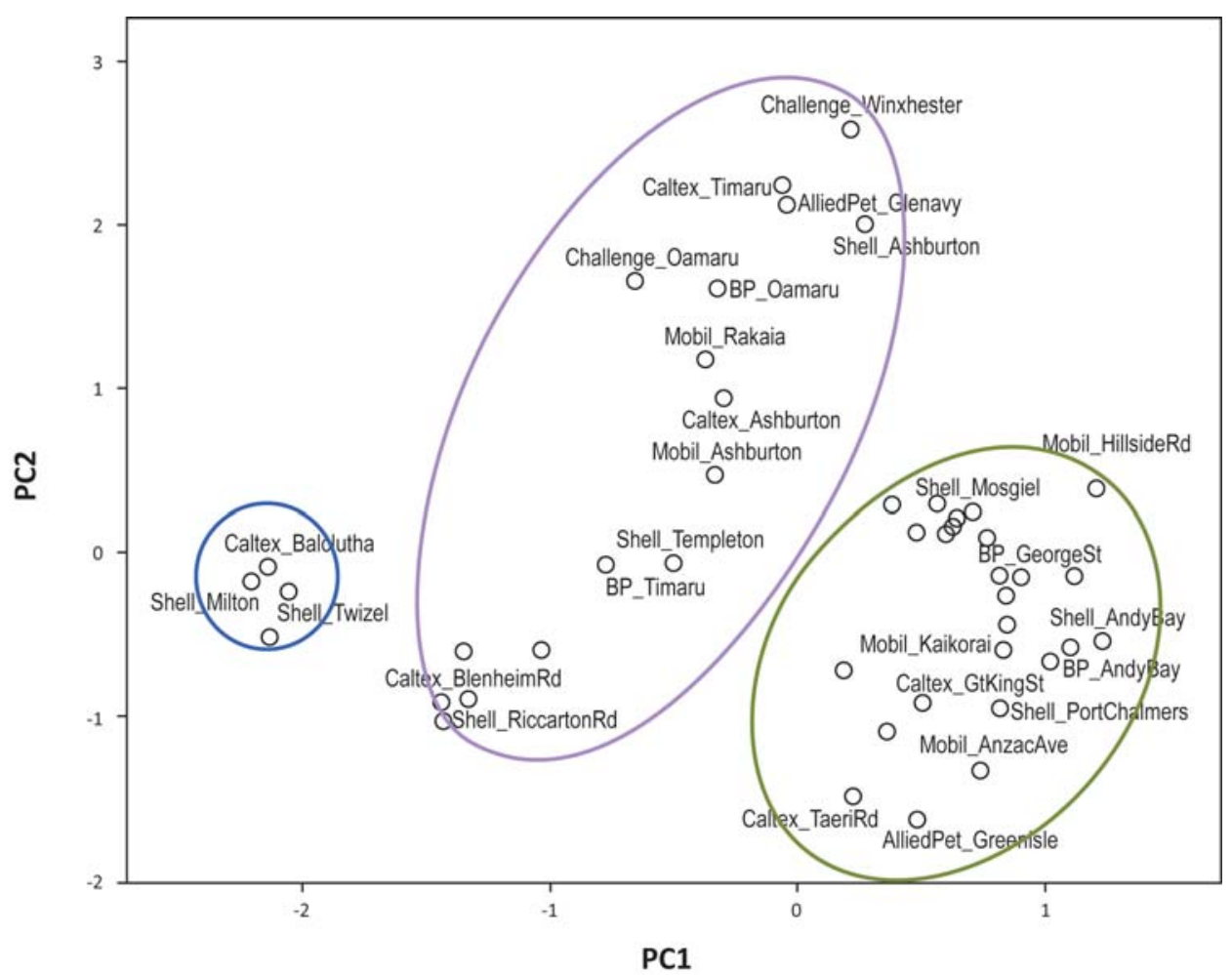

Fig. 6

Scores plot for principal component analysis. It holds the scores for each sample on PC1 and PC2. The names of some samples were removed for easier visualisation. Distinct clustering can be seen for samples from Dunedin City (right), Canterbury region and North Otago (central), and South Otago and Twizel (left) 


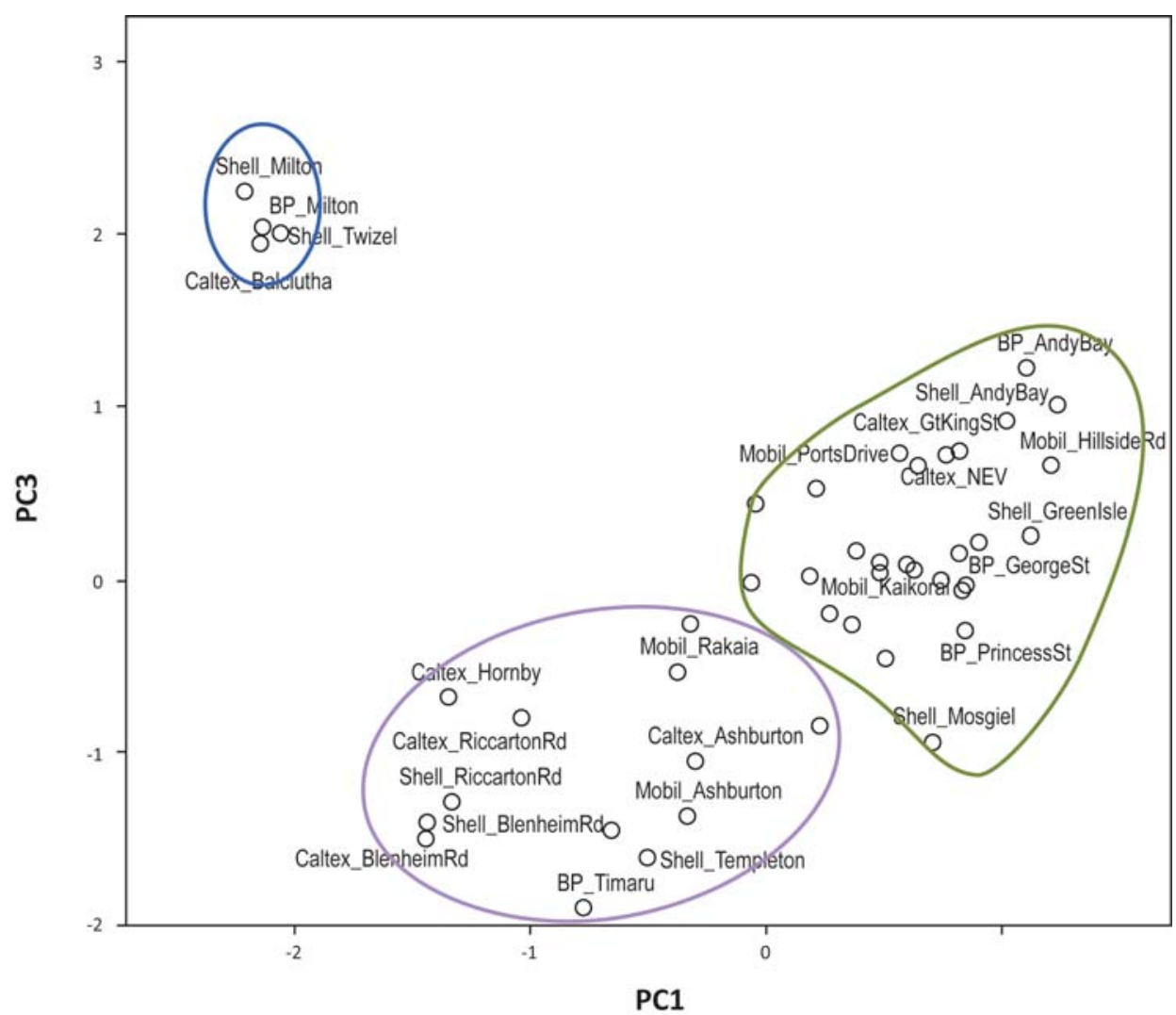

Fig. 7

Scores plot for principal component analysis. It holds the scores for each sample on PC1 and PC3. The names of some samples were removed for easier visualisation. Distinct clustering can be seen for samples from Dunedin City (right), Canterbury region and North Otago (central), and South Otago and Twizel (left)

Dunedin area and another containing the South Otago and Twizel samples. The cluster that contained the samples from the Canterbury region and North Otago area only indicated a moderate correlation, as can be seen in the scores plot.

PCA was then used to identify the variables that contributed most to the variance of the data set. Table 2 shows the component matrix which listed all the variables and their contribution to the data set variability. The compounds that contributed the most are those with the largest values in the positive and negative directions. The top contributors to PC1 are the $\delta^{2} \mathrm{H}$ values of $n \mathrm{C}_{15}, n \mathrm{C}_{16}$ and $n \mathrm{C}_{17}$ with highly positive coefficients $(>0.9)$ but the $\delta^{13} \mathrm{C}$ values of these compounds provided little weight in the interpretation of the scores for the same principal component. Furthermore, PC1 had an almost evenly strong contribution from the rest of the variables for both $\delta^{13} \mathrm{C}$ and $\delta^{2} \mathrm{H}$ values. In PC2, based on the $\delta^{13} \mathrm{C}$ 
Table 2

Component matrix which shows variables and their contribution to the variance in the data set. Results are based on the $\delta 1^{3} \mathrm{C}$ and $\delta^{2} \mathrm{H}$ values of the alkane compounds

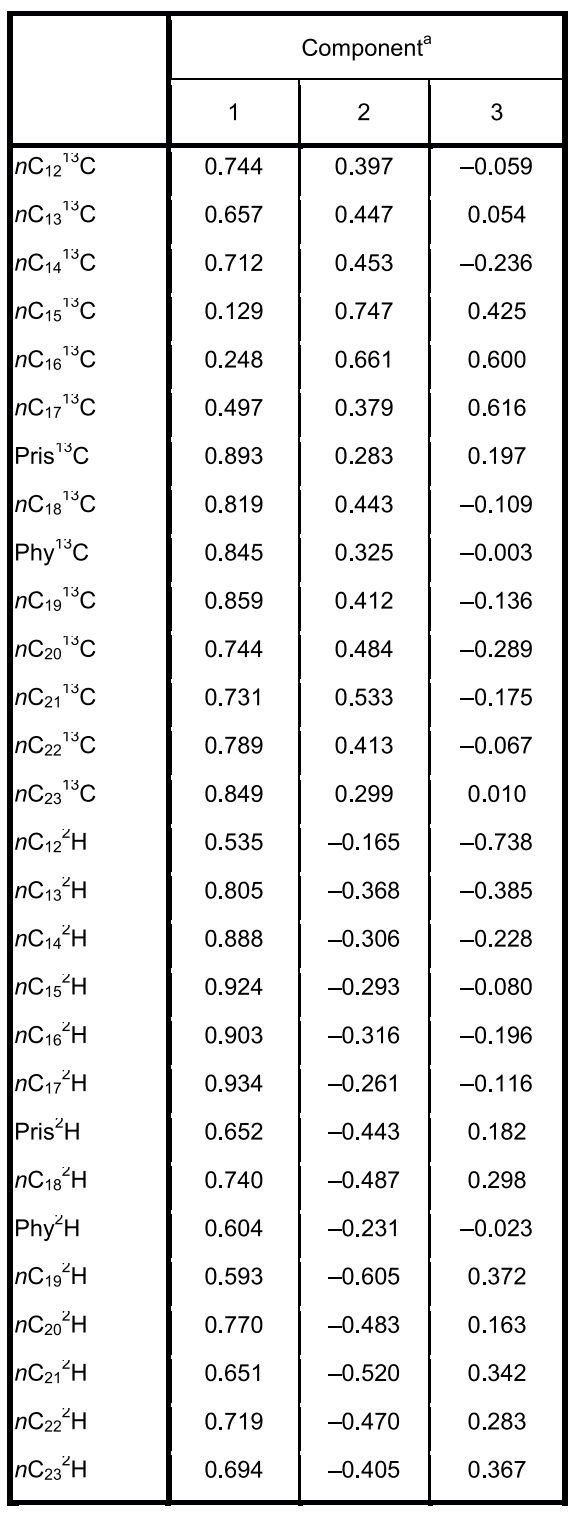

a 3 components extracted. values, the loadings were almost equally weighted between all the alkanes ranging from 0.283 to 0.533 except for $n \mathrm{C}_{15}$ and $n \mathrm{C}_{16}$ which showed relatively high value of 0.747 and 0.661 . Meanwhile, the hydrogen isotope ratios of alkanes within the diesel samples showed negative coefficients when compared with $\delta^{13} \mathrm{C}$ values, suggesting an inverse relationship between these two stable isotopic values of the same compounds. However, no obvious differences in the loadings of the $\delta^{2} \mathrm{H}$ values could be detected between the variables, indicating that all the alkane compounds are equally important in describing the variation between the samples based on PC2. Hence, it is rather obvious that PC2 allowed clustering based on the different stable isotope components used in the data set (Fig. 6).

For PC3, several alkane compounds, $n \mathrm{C}_{15}$ to $n \mathrm{C}_{17}$, had the greatest weight in the interpretation of the scores with positive coefficients for $\delta^{13} \mathrm{C}$ values. On the other hand, the shorter chain alkanes $\left(n \mathrm{C}_{12}-n \mathrm{C}_{14}\right)$ gave more weight in the loadings to the $\delta^{2} \mathrm{H}$ values, although in the opposite direction from that of the $\delta^{13} \mathrm{C}$ values. When the scores plots of PC1 and PC3 were plotted together as shown in Fig. 7, PC3 separated the South Otago and Twizel samples from the rest of the set, suggesting that the shorter chain length alkanes were the components that contributed the most to the clustering. This finding may infer that the factor which led the South Otago and Twizel samples to be very distinct from the remaining samples was caused by the differences in stable 
isotope values within these alkanes. These differences can be due to physical weathering. This reasoning was based on previously published work (Stout et al. 2001; Wang and Brown 2008), which indicated that the shorter chain-length alkanes are more susceptible to any form of weathering process. In all likelihood, evaporation could happen at some stage during the transfer from the refinery to the service stations. It has been determined that shorter chain-length alkanes indeed show isotopic fractionation rising from evaporation in previous studies (Wang and Huang 2001, 2003; Muhammad et al. 2013). Also, it is important to note that the residual diesel in the storage tanks at these stations could be mixed with additional fillings, thus changing the stable isotope compositions within the diesel to a certain extent.

Hierarchical clustering analysis was performed to determine if variability in the data set of the diesel fuel analysis could account for the relatedness between samples. Figure 8 is a dendrogram derived using Ward's linkage method showing a cluster relationship between the 45 diesel samples. Cluster analysis yielded a very similar picture shown by PCA. Samples from different locations in the Dunedin area implied a very close relationship. The same relatedness was observed for the samples which were obtained from the Canterbury region and North Otago. In addition, the distinct clustering of South Otago and Twizel diesel samples from the rest of the set demonstrated by PCA held true as seen in the dendrogram.

\section{Conclusions}

In the present study, CSIA had been used to determine the carbon and hydrogen isotopic composition of the alkanes within 45 diesel samples from different locations in the South Island of New Zealand. Wide ranges of $\delta^{13} \mathrm{C}$ and $\delta^{2} \mathrm{H}$ values were determined for the ubiquitous alkane compounds (the greatest values being $-4.5 \%$ and $-40 \%$, respectively). PCA and hierarchical clustering analyses of the stable isotope values within the alkanes suggested that diesel fuel samples obtained from different locations were distinguishable. The key components in the differentiation of these diesel fuel samples are the $\delta^{2} \mathrm{H}$ values of the shorter chain-length alkanes, compounds that are known to be susceptible to weathering. However, due to the sampling being a one-off event and the information on fuel delivery schedule to various stations by trucks was not accessible, possible reasons for diesel fuel discrimination as observed in this study (i.e. geographic origin, diesel fuel's residence time or replenishment regime of a storage tank at a service station), may be purely coincidental and there should be no implication of a factor such as geographic discrimination per se.

The subtle differences of the hydrogen isotopic compositions within the alkanes of different diesel samples highlighted the power of CSIA as a means of differentiating petroleum products from different origins, even more so when two or more stable isotopes systems are combined. While the stable isotope 
measurements may provide information to classify a sample at a broad scale (rural versus urban origin), much more detailed information is required on the temporal and spatial variability of diesel fuel compositions. The pattern and linkage(s) found among these samples, if combined with the identification of the driver(s) or commonality that induces the changes in the isotopic composition of the samples, provide a good basis for many applications such as forensic investigation.

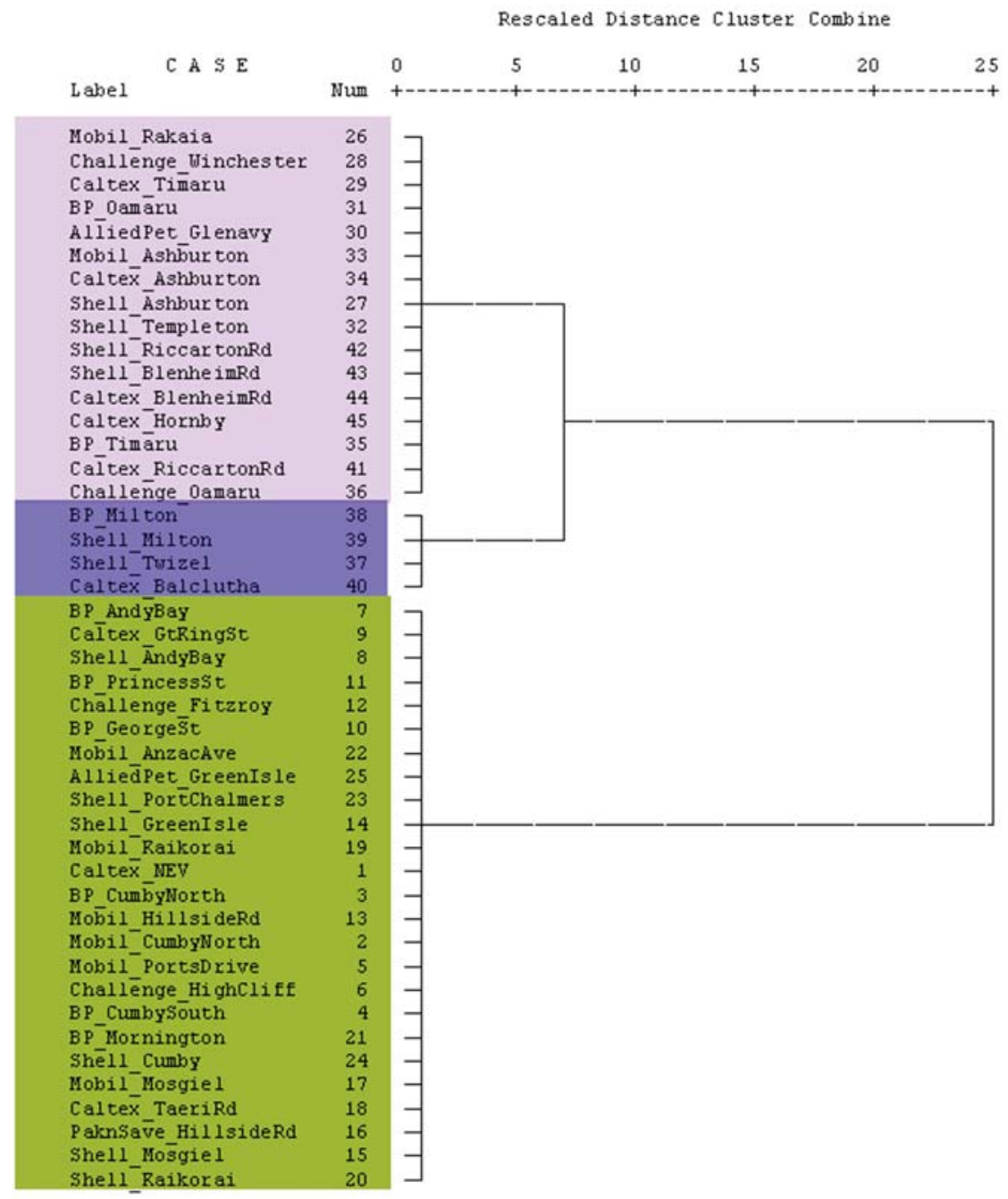

Fig. 8

Dendrogram using Ward's Linkage method showing cluster relationship between samples. Lengths of vertical lines represent statistical difference between multivariate components in each sample. Distinct clustering can be seen for samples from Dunedin City (lower), Canterbury region and North Otago (upper), and South Otago and Twizel (mid) 


\section{Acknowledgements}

SAM acknowledges the support from Ministry of Higher Education Malaysia and Universiti Sains Malaysia for her studies.

\section{References}

Asif, M., K. Grice, T. Fazeelat 2009: Assessment of petroleum biodegradation using stable hydrogen isotopes of individual saturated hydrocarbon and polycyclic aromatic hydrocarbon distributions in oils from the Upper Indus Basin, Pakistan. - Organic Geochemistry, 40/3, pp. 301-311.

Bayliss, G.S. 1968: In formation of pristane, phytane, and related isoprenoid hydrocarbons by the thermal degradation of chlorophyll. - National Meeting of the American Chemical Society, San Francisco, CA, pp. F117-F131.

Bilke, S., A. Mosandl 2002: Measurements by gas chromatography/pyrolysis/mass spectrometry: Fundamental conditions in $2 \mathrm{H} / 1 \mathrm{H}$ isotope ratio analysis. - Rapid Communications in Mass Spectrometry, 16/5, pp. 468-472.

Boyd, T.J., R.B. Coffin 2004: Use of stable carbon isotopes and multivariate statistics to sourceapportion fuel hydrocarbons. - Environmental Research, Engineering and Management, 4/30, pp. 28-35.

Boyd, T.J., C.L. Osburn, K.J. Johnson, K.B. Birgl, R.B. Coffin 2006: Compound-specific isotope analysis coupled with multivariate statistics to source-apportion hydrocarbon mixtures. - Environmental Science and Technology, 40/6, pp. 1916-1924.

Dempster, H.S., B. Sherwood Lollar, S. Feenstra 1997: Tracing organic contaminants in groundwater A new methodology using compound-specific isotopic analysis. - Environmental Science \& Technology, 31/11, pp. 3193-3197.

Freeman, K.H., J.M. Hayes, J.-M., Trendel, P. Albrecht 1990: Evidence from carbon isotope measurements for diverse origins of sedimentary hydrocarbons. - Nature, 343/6255, pp. 254-256.

Fuex, A.N. 1977: The use of stable carbon isotopes in hydrocarbon exploration. - Journal of Geochemical Exploration, 7, pp. 155-188.

Gaines, R.B., G.J. Hall, G.S. Frysinger, W.R. Gronlund, K.L. Juaire 2006: Chemometric determination of target compounds used to fingerprint unweathered diesel fuels. - Environmental Forensics, 7/1, pp. 77-87.

Harrington, R.R., S.R. Poulson, J.I. Drever, P.J.S. Colberg, E.F. Kelly 1999: Carbon isotope systematics of monoaromatic hydrocarbons: Vaporization and adsorption experiments. - Organic Geochemistry, 30/8, pp. 765-775.

Harvey, S.D., K.H. Jarman, J.J., Moran, C.M. Sorensen, B.W. Wright 2012: Characterization of diesel fuel by chemical separation combined with capillary gas chromatography (GC) isotope ratio mass spectrometry (IRMS). - Talanta, 99, pp. 262-269.

Kazi, T.G., M.B. Arain, M.K. Jamali, N. Jalbani, H.I. Afridi, R.A. Sarfraz, J.A. Baig, A.Q. Shah 2009: Assessment of water quality of polluted lake using multivariate statistical techniques: A case study. - Ecotoxicology and Environmental Safety, 72/2, pp. 301-309.

Kelley, C.A., B.T. Hammer, R.B. Coffin. 1997: Concentrations and stable isotope values of BTEX in gasoline-contaminated groundwater. - Environmental Science \& Technology, 31/9, pp. 2469-2472.

Kendall, C., E.A. Caldwell 1998: Fundamentals of isotope geochemistry. - In: Kendall, C., J.J. McDonnell (Eds): Isotope Tracers in Catchment Hydrology. Elsevier Science: Amsterdam, pp. $51-86$.

Li, M., Y. Huang, M. Obermajer, C. Jiang, L.R. Snowdon, M.G. Fowler 2001: Hydrogen isotopic compositions of individual alkanes as a new approach to petroleum correlation: Case studies from the Western Canada Sedimentary Basin. - Organic Geochemistry, 32/12, pp. 1387-1399. 
Lichtfouse, E. 2000: Compound-specific isotope analysis. Application to archaelogy, biomedical sciences, biosynthesis, environment, extraterrestrial chemistry, food science, forensic science, humic substances, microbiology, organic geochemistry, soil science and sport. - Rapid Communications in Mass Spectrometry, 14/15, pp. 1337-1344.

Matthews, D.E., J.M. Hayes 1978: Isotope-ratio-monitoring gas chromatography-mass spectrometry. Analytical Chemistry, 50/11, pp. 1465-1473.

McRae, C., G.D. Love, I.P. Murray, C.E. Snape, A.E. Fallick 1996: Potential of gas chromatography isotope ratio mass spectrometry to source polycyclic aromatic hydrocarbon emissions. Analytical Communications, 33/9, pp. 331-333.

McRae, C., C.E. Snape, C.-G. Sun, D. Fabbri, D. Tartari, C. Trombini, A.E. Fallick 2000: Use of compound-specific stable isotope analysis to source anthropogenic natural gas-derived polycyclic aromatic hydrocarbons in a lagoon sediment. - Environmental Science \& Technology, 34/22, pp. 4684-4686.

Meier-Augenstein, W. 1999: Applied gas chromatography coupled to isotope ratio mass spectrometry. - Journal of Chromatography A, 842/1-2, pp. 351-371.

Muhammad, S.A., A.R. Hayman, R. Van Hale, R.D. Frew. 2013: Assessing carbon and hydrogen isotopic fractionation of diesel fuel $n$-alkanes during progressive evaporation. - Journal of Forensic Sciences, (n press).

Muthukumar, N., S. Mohanan, S. Maruthamuthu, P. Subramanian, N. Palaniswamy, M. Raghavan 2003: Role of Brucella sp. and Gallionella sp. in oil degradation and corrosion. Electrochemistry Communications, 5/5, pp. 421-425.

Négrel, P., M. Blessing, R. Millot, E. Petelet-Giraud, C. Innocent 2012: Isotopic methods give clues about the origins of trace metals and organic pollutants in the environment. - TrAC Trends in Analytical Chemistry, 38, pp. 143-153.

O'Malley, V.P., T.A. Abrajano, J. Hellou 1996: Stable carbon isotopic apportionment of individual polycyclic aromatic hydrocarbons in St. John's Harbour, Newfoundland. - Environmental Science \& Technology, 30/2, pp. 634-639.

O'Sullivan, G., R.M. Kalin 2008: Investigation of the range of carbon and hydrogen isotopes within a global set of gasolines. - Environmental Forensics, 9/2-3, pp. 166-176.

Pasadakis, N., E. Gidarakos, G. Kanellopoulou, N. Spanoudakis 2008: Identifying sources of oil spills in a refinery by gas chromatography and chemometrics: A case study. - Environmental Forensics, 9/1, pp. 33-39.

Philp, R.P. 2007: The emergence of stable isotopes in environmental and forensic geochemistry studies: A review. - Environmental Chemistry Letters, 5/2, pp. 57-66.

Philp, R.P., J. Allen, T. Kuder 2002: The use of the isotopic composition of individual compounds for correlating spilled oils and refined products in the environment with suspected sources. Environmental Forensics, 3/3-4, pp. 341-348.

Schmitt, J., B. Glaser, W. Zech 2003: Amount-dependent isotopic fractionation during compoundspecific isotope analysis. - Rapid Communications in Mass Spectrometry, 17/9, pp. 970-977.

Smallwood, B.J., R.P. Philp, J.D. Allen 2002: Stable carbon isotopic composition of gasolines determined by isotope ratio monitoring gas chromatography mass spectrometry. - Organic Geochemistry, 33/2, pp. 149-159.

Smallwood, B.J., R.P. Philp, T.W. Burgoyne, J.D. Allen 2001: The use of stable isotopes to differentiate specific source markers for MTBE. - Environmental Forensics, 2/3, pp. 215-221.

Speight, J.G. 2007: The Chemistry and Technology of Petroleum. 4th ed. - CRC Press: New York.

Stout, S.A., A.D. Uhler, K.J. McCarthy 2001: A strategy and methodology for defensibly correlating spilled oil to source candidates. - Environmental Forensics, 2/1, pp. 87-98.

Sun, Y., Z. Chen, S. Xu, P. Cai 2005: Stable carbon and hydrogen isotopic fractionation of individual nalkanes accompanying biodegradation: Evidence from a group of progressively biodegraded oils. - Organic Geochemistry, 36/2, pp. 225-238. 
Sun, Y., S. Xu, H. Lu, P. Cuai 2003: Source facies of the Paleozoic petroleum systems in the Tabei uplift, Tarim Basin, NW China: Implications from aryl isoprenoids in crude oils. - Organic Geochemistry, 34/4, pp. 629-634.

Thullner, M., F. Centler, H.-H. Richnow, A. Fischer 2012: Quantification of organic pollutant degradation in contaminated aquifers using compound specific stable isotope analysis - Review of recent developments. - Organic Geochemistry, 42/12, pp. 1440-1460.

Wang, Y., Y. Huang 2001: Hydrogen isotope fractionation of low molecular weight n-alkanes during progressive vaporization. - Organic Geochemistry, 32/8, pp. 991-998.

Wang, Y., Y. Huang 2003: Hydrogen isotopic fractionation of petroleum hydrocarbons during vaporization: Implications for assessing artificial and natural remediation of petroleum contamination. - Applied Geochemistry, 18/10, pp. 1641-1651.

Wang, Z., C. Brown 2008: Chemical fingerprinting of petroleum hydrocarbons. - In: Mudge, S.M. (Ed.): Methods in Environmental Forensics. CRC Press: Boca Raton, pp. 43-112.

Wang, Z., M. Fingas, D.S. Page 1999: Oil spill identification. - Journal of Chromatography A, 843/1-2, pp. 369-411. 